\title{
La ironía en el caso de las "hamburguesas gigantes”, España, 2006
}

The irony in the case of The giant hamburgers, Spain, 2006.

\author{
José Antonio Díaz Rojo \\ CSIC-Universitat de València, Instituto de Historia de la Medicina y de la Ciencia. 446003 Valencia, \\ España. Correo electrónico: jose.a.diaz@uv.es
}

El objetivo de este artículo es analizar el empleo de la ironía como recurso retórico y sus manifestaciones lingüísticas en el discurso periodístico sobre las controversias biopolíticas en torno a la salud, mediante el estudio de un caso: una noticia aparecida en el diario español El Mundo el 16 de noviembre del 2006, y cuyo tema era la polémica sobre las "hamburguesas gigantes" suscitada entre el Ministerio de Sanidad y Consumo, y la cadena de restaurantes Burger King. La finalidad del empleo de la estrategia irónica en esta controversia periodística es rechazar la postura del adversario aceptando parcialmente uno de sus argumentos irrebatibles, pero rebajando su importancia y su gravedad, mediante la ridiculización.

Palabras clave: retórica, argumentación, periodismo, salud, biopolítica.

The aim of this paper is to analyze the use of irony as a rhetorical device and its linguistic forms in journalistic discourse on the biopolitical controversies concerning health. The case study, a news item appearing in the Spanish newspaper El Mundo on $16^{\text {th }}$ November 2006, deals with the controversy arising between the Ministry of Health and Consumer Affairs and the Burger King Company over "giant hamburgers". The reason behind using an ironic strategy in this journalistic controversy is to reject the opponent's position by partially accepting one of their irrefutable arguments, but understating its importance and seriousness by employing ridicule.

Key words: rhetorics, argumentation, journalism, health, biopolitics.

\section{INTRODUCCIÓN}

Este trabajo tiene como objetivo analizar el empleo de la ironía como recurso retórico en el discurso periodístico sobre las controversias biopolíticas en torno a la salud, mediante el estudio de un caso: una noticia titulada "El tamaño sí importa", aparecida en el diario español El Mundo el día 16 de noviembre del 2006, y cuyo tema era la polémica sobre las "hamburguesas gigantes" suscitada entre el Ministerio de Sanidad y Consumo y la cadena de restaurantes Burger King. Se trata de una noticia construida y vertebrada sobre la ironía expresada mediante diversos recursos 
o mecanismos lingüísticos, que puede servir para ilustrar el empleo de esta figura y de sus manifestaciones lingüísticas como técnica argumentativa en una controversia social en general, y biopolítica en particular.

Podemos definir el concepto de biopolítica como la acción de dirigir y controlar las capacidades biológicas del ser humano por parte de los poderes públicos. Los campos en que actúa la biopolítica son diversos: la educación para la salud en materia de estilos de vida, como las campañas sanitarias antiobesidad, antitabaco o antialcohol o las políticas para adquirir hábitos alimentarios saludables; las vacunas para prevenir enfermedades; las campañas para reducir las muertes por accidentes de tráfico a través de medidas como el carné por puntos; las ayudas a las familias para fomentar la natalidad, etc.

El debate biopolítico plantea la disyuntiva entre Estado paternalista o intervencionista y Estado protector, esto es, entre la postura que defiende que los gobiernos no deben intervenir en los hábitos y estilos de vida de los ciudadanos en materia de alimentación, costumbres, sexo y consumo de alcohol y tabaco, pues la intervención política supondría coartar la libertad de elección de las personas, y la postura de quienes creen que un Estado responsable debe regular las conductas sociales como parte de las políticas de salud pública para prevenir enfermedades sociales y reducir el gasto público.

La polémica sobre las "hamburguesas gigantes" surgió a raíz del lanzamiento de una campaña publicitaria de la empresa Burger King para promocionar hamburguesas de gran tamaño de 971 kilocalorías, en noviembre de 2006. Anteriormente, las cadenas de alimentación habían firmado un acuerdo de autorregulación con el Ministerio de Sanidad y Consumo español por el que se comprometían a no dar publicidad ni incentivar el consumo de raciones individuales o productos grandes. El ministerio entendió que la campaña de Burger King incumplía el compromiso adquirido por la empresa de restauración, ante lo que le solicitó la retirada de los anuncios de la "hamburguesa gigante", a lo que la cadena alimentaria hizo caso omiso, lo que llevó al ministerio a declarar nulo o roto el acuerdo con Burger King.

La ironía no es una estrategia retórica habitual y frecuente en el periodismo informativo, y menos una macroestrategia argumentativa para organizar textualmente toda una noticia, pero no está totalmente ausente en este género, como veremos a continuación. El caso que presentamos y analizamos es una muestra del empleo de la ironía como recurso argumentativo para rechazar la postura del adversario por parte del periódico en la controversia sobre la intervención del Estado en los estilos de vida, aceptando parcialmente uno de sus argumentos irrebatibles, pero rebajando su importancia y su gravedad, mediante la ridiculización.

Este caso es relevante no sólo desde el punto de vista particular de la retórica de las controversias biopolíticas en la prensa, sino desde la perspectiva general de la retórica periodística y la retórica general, por tres razones: a) ilustra el uso de la ironía para expresar una actitud periodística ante un debate biopolítico; b) es un ejemplo representativo del uso de la ironía en el periodismo informativo; c) es una muestra del valor argumentativo de la ironía como técnica de réplica para rechazar el argumento del adversario, realizando dos acciones aparentemente contrapuestas de aceptación y rechazo simultáneo: aceptar un argumento difícil de rebatir y rebajar su importancia y gravedad mediante su ridiculización, con el fin de rebajar o anular su fuerza argumentativa. Si desde el punto de vista de la retórica elocutiva es una figura de ficción ligada a la sermocinatio, desde el punto de vista de la retórica argumentativa es una 
forma de concessio. Ésta es una figura dialéctica que "consiste en reconocer que la parte contraria lleva razón en un aspecto del asunto sobre el que disputa [...][pero] esta actitud esconde un giro en sentido inverso, pues el punto en el que el autor o litigante reconoce su error es presentado como algo intrascendente en comparación con el tema central, donde su postura sí resulta incuestionable" (Azaustre, 2006: 133)

\section{LA IRONÍA COMO RECURSO RETÓRICO Y SU FUNDAMENTO PRAGMÁTICO-ENUNCIATIVO}

La retórica define la ironía como "la expresión de un pensamiento a través de un enunciado de sentido literal diferente o incluso opuesto a lo que en el fondo se piensa y se pretende decir; de manera tácita, el contexto aporta las claves necesarias para la correcta interpretación de este discurso [...]". (Azaustre, 2006: 89).

Suele afirmarse que la descripción de la ironía que aportaba la retórica clásica era deficiente o insuficiente, y que las modernas ciencias del lenguaje, especialmente la pragmática, han ofrecido una explicación lingüística más profunda y con gran fuerza interpretativa de este fenómeno, desde la teoría polifónica de la enunciación, la teoría de la argumentación o la teoría de la relevancia, que arrojan nueva luz sobre las claves de este recurso (Salvador, 2003). En parte esto es cierto, pero debemos recordar que el más importante estudioso de la retórica del siglo XX, Lausberg, afirmaba, años antes del desarrollo de los estudios pragmáticos, que la ironía "puede considerarse como una sermocinatio [reproducción del discurso de un personaje] con el disfraz del adversario" (1966-69: 241), anticipando el valor polifónico y argumentativo de esta figura, puesto de relieve y desarrollado más tarde por la pragmática en los años 80 , y supuestamente considerado mero ornamento para la retórica clásica. Por su parte, Morata Garavelli (1988: 303) sostiene:

La simulatio, en la práctica oratoria, se presentaba como un acuerdo fingido con las tesis del adversario, mediante aparentes afirmaciones o exhortaciones.

Desde el punto de vista de la enunciación, en la ironía coexisten dos enunciadores: un enunciador jocoso $\mathrm{E}_{1}$ que intenta desacreditar implícitamente a un $\mathrm{E}_{2}$ opuesto. Siguiendo a Ducrot (1984), el locutor L emite un enunciado que contiene literalmente la postura de un enunciador E, pero no la asume y la considera absurda. Esta tesis absurda del enunciador E es transmitida en el enunciado irónico por el locutor L, pero éste no se responsabiliza de ella, burlándose de su contenido. Berrendonner (1982: 162) sostiene que "ironizar sería producir un enunciado utilizándolo no como uso (para hablar de la realidad), sino como mención (para hablar de él, y significar la distancia que se toma al respecto)". Según Haverkate, la ironía es un mecanismo de cortesía que oculta las verdaderas intenciones del hablante. Como acto de habla, este autor la considera una violación transparente de la máxima de sinceridad, a diferencia de la mentira, que vulnera esta máxima de forma encubierta. Es una insinceridad manifiesta que pretende producir determinados efectos retóricos en el interlocutor.

Retóricamente, la ironía es un recurso complejo de distanciamiento y de simulación manifiesta y explícita ligado a otras figuras retóricas. Si desde el punto de vista de la retórica elocutiva es una figura de ficción vinculada a la simulatio (fingimiento) y a 
la sermocinatio (reproducir el discurso ajeno), desde el punto de vista de la retórica argumentativa es una forma de concessio. Ésta es una figura dialéctica que "consiste en reconocer que la parte contraria lleva razón en un aspecto del asunto sobre el que disputa [...][pero] esta actitud esconden un giro en sentido inverso, pues el punto en el que el autor o litigante reconoce su error es presentado como algo intrascendente en comparación con el tema central, donde su postura sí resulta incuestionable" (Azaustre, 2006: 133).

\section{ANÁLISIS RETÓRICO-ARGUMENTATIVO DE LA NOTICIA}

La noticia publicada por El Mundo en la sección "España" informa de la decisión del Ministerio de Sanidad y Consumo español de demandar a Burger King la retirada de su campaña publicitaria de una hamburguesa de casi 1000 kilocalorías, por incumplimiento de un acuerdo de autorregulación firmado entre el departamento ministerial y la organización empresarial de restaurantes "modernos", así como da cuenta de la reacción de la cadena de restauración de mantener sus anuncios, desoyendo la petición gubernamental.

\subsection{EL TITULAR: LA IRONÍA COMO RUPTURA ESTILÍSTICA, DOBLE POLIFONÍA Y FUNCIÓN APELATIVA}

El titular de la noticia es llamativo y presenta un estilo y un tono poco frecuente en la información periodística, que sorprende porque se aleja totalmente del resto de los titulares de las noticias publicadas por otros periódicos que también cubrieron la polémica. El titular de El Mundo dice así: "El tamaño sí importa". Otros medios mencionaban en sus titulares a los actores participantes en el hecho, así como las acciones emprendidas por ellos:

Sanidad pide a Burger King que retire los anuncios de sus hamburguesas gigantes ( $E l$ País, 16-11-2006).

Sanidad inicia una campaña contra la publicidad de hamburguesas gigantes (Sur Digit@l, 16-11-2009).

Sanidad pide retirada campaña de hamburguesa que incita a la obesidad (20 minutos, 15-11-2006).

Sanidad pide a Burger King que retire una campaña por incitar al sobrepeso ( $L a$ Voz de Galicia, 6-11-2006)

Sanidad exige a Burger King que deje de incitar a consumir hamburguesas de gran tamaño (Diario de Ibiza.es, 16-11-2006).

El titular de El Mundo rompe con las prácticas discursivas habituales del periodismo informativo y omite deliberadamente la mención a las partes implicadas en la polémica y a sus acciones (el quién y el qué). En el titular predomina la función apelativa, pues el redactor renuncia a informar en profundidad y pretende llamar la 
atención del lector de un hecho desconocido mediante un enunciado breve y sorprendente, cuyo sentido real conocerá el receptor leyendo la noticia completa.

En un alarde de originalidad, el redactor hace referencia a la "importancia del tamaño", evocando las creencias populares, más o menos chistosas o maliciosas, en torno a la importancia del tamaño del pene como condición para proporcionar placer sexual a la mujer. En el titular se afirma que el tamaño sí importa, alterando la frase hecha según la cual el tamaño del miembro viril no importa, es decir, no influye en el goce sexual de la mujer. Sin más información, el titular parece remitir al tamaño del pene, y de esa interpretación inicial parte el lector para seguir leyendo la noticia.

El periodista, por tanto, usa una estrategia polifónica, pues incorpora a su texto el discurso de un enunciador ajeno, el Ministerio de Sanidad y Consumo español, que considera importante y decisivo el tamaño de una hamburguesa, pero sin desvelárselo al lector. Éste aún desconoce que se trata de un discurso ajeno, así como la identidad del enunciador, jugando el autor con el misterio o el enigma. El redactor, pues, incorpora en el titular el punto de vista ministerial, pero se distancia de él rechazándolo mediante la ridiculización, y para ello emplea la ironía, incorporando un segundo discurso ajeno transformado y fundido con el primero.

El periodista hace uso del discurso de la vox populi, es decir, del discurso colectivo de las creencias compartidas socialmente en torno a la importancia del pene, cristalizadas en la unidad fraseológica El tamaño no importa. El autor inserta en su texto este enunciado fraseológico, pero para hacerlo coincidir con el discurso ministerial que concede importancia al tamaño, lo somete a una modificación de la estructura formal y del contenido semántico que invierte el significado original. Mediante una sustitución del adverbio no por sí, afirmando que el tamaño sí es importante, el titular incorpora la opinión mantenida por el ministerio aplicada a la "hamburguesa gigante" de Burger King.

El periodista, por tanto, se burla de la opinión ministerial por medio de la ironía, reproduciendo el parecer de las autoridades sanitarias sobre el tamaño de la hamburguesa, pero distanciándose de él mediante una operación retórica que consiste en la amalgamación discursiva con el discurso popular sobre el tamaño del pene. De esta forma, el redactor logra quitar seriedad al tamaño de la hamburguesa, al evocar en la mente del lector de forma jocosa el tamaño del pene.

Esta asunción del discurso ministerial es irónica, pues de la lectura completa del texto el lector extraerá la conclusión de que, para el redactor, el tamaño (no del pene, sino de la hamburguesa, como más tarde descubrirá el receptor) no es realmente importante, ridiculizando así el argumento del ministerio, para el que el gran tamaño de la ración tiene una importancia decisiva, ya que el tamaño excesivo aumenta sus calorías, incrementando de esta forma el riesgo de obesidad.

La omisión de los agentes sociales protagonistas de la noticia y la alusión jocosa a lo sexual como analogía -aún no desvelada- entre el pene y la hamburguesa es una estrategia para predisponer al receptor a leer el resto del texto como un divertimento, aún cuando el lector ignora todavía el tema y el contenido de la noticia. El redactor, al tiempo que reduce la importancia y seriedad del asunto sobre el que versará la pieza periodística, desplaza el interés y el foco de la noticia, pues la sitúa en el ámbito del humor, de la mera curiosidad o del pintoresquismo, y no en el campo de una controversia seria e importante sobre la salud. 


\subsection{EL SUBTÍTULO COMO ENUNCIADO COMPLEMENTARIO NO IRÓNICO: LOS ELEMENTOS INFORMATIVOS CLÁSICOS}

El titular irónico aporta poca información denotativa o representativa, pero contiene valiosa información apelativa y connotativa, ya que: a) atrae la atención del lector por la alusión sexual; b) orienta el tono jocoso de la noticia; y c) expresa implícitamente la actitud desfavorable hacia el ministerio. Esta falta de información denotativa obliga al redactor a incluir un subtítulo informativo que aporte datos relevantes sobre el hecho noticioso. Para construirlo, vuelve a los cánones retóricos e incluye un enunciado complementario del titular redactado de acuerdo con los principios estilísticos clásicos de la información periodística, indicando el quién y el qué del relato:

Sanidad denuncia la campaña XXL de Burger King porque no cumple los acuerdos de la propia industria contra la obesidad

El subtítulo describe una acción comunicativa del ministerio, denunciar, que describe y valora la conducta verbal de dicho agente. Se trata de un verbo de comunicación con un tono amenazante, que si bien no llega a poseer una intención agresiva, presenta al actor que la realiza como un agente que evalúa negativamente la acción de otro actor, pero manteniendo la cortesía verbal hacia él. Es interesante notar, por otra parte, que el redactor emplea el verbo cumplir en forma negativa, no cumple, a diferencia de los titulares de otros periódicos, que usan incumplir. No cumplir es una forma atenuada de incumplir, lo que es una marca retórica de la estrategia de rebajar la gravedad de la acción llevada a cabo por la empresa al no respetar el acuerdo de autorregulación. A pesar de ello, el redactor enfatiza que es la misma industria y no otro agente quien se ha comprometido a luchar contra la obesidad por medio del adjetivo propia en el sintagma la propia industria.

\subsection{LA ENTRADILLA: RECURSOS IRÓNICOS}

La entrada de la noticia arranca de nuevo con una alusión al tamaño, en forma de interrogación retórica, otra figura poco frecuente en las prácticas discursivas del periodismo informativo, cercana a la simulación: “¿Quién dijo que el tamaño no importa?". Con este enunciado, el redactor desmiente la vox populi, que es el enunciador colectivo que afirma que el tamaño no importa, para asumir irónicamente el punto de vista del ministerio, que defiende la idea contraria. Y sigue diciendo: "Aquí viene todo un ministerio a desmentir semejante mentira: Sanidad denuncia que la campaña publicitaria XXL de Burger King incumple [...]”.

El periodista emplea una estrategia predicativa para referirse a Sanidad: la construcción todo un ministerio, en que usa irónicamente la fórmula ponderativa todo + $u n+$ sustantivo, con el fin de aludir de forma peyorativa y despreciar al ministerio enfrentado a Burger King. Esta combinación es un sintagma predicativo con "valor enfático [...] que indica que un elemento de una clase posee la propiedad característica en su valor más alto" (Leonetti, 1999: 846). Ridiculiza así la visión que los ciudadanos tienen de un ministerio como una institución muy importante que dirige una política sectorial de un país. Además, califica de mentira el discurso ajeno colectivo que concede importancia al tamaño. El redactor ironiza adoptando una postura falsamente 
grave y seria al emplear el sustantivo de valoración muy negativa mentira, que además enfatiza con el adjetivo semejante. Emplea así otra forma irónica, la hipérbole, para intensificar burlonamente hasta el grado de mentira el carácter erróneo o falso de la idea de que el tamaño no importa. Nuevamente el redactor aparenta asumir el discurso ministerial que defiende el argumento de que el tamaño es importante, pero mediante la ironía rechaza dicho argumento.

\subsection{EL CUERPO DE LA NOTICIA: LA IRONÍA PERIODÍSTICA COMO RECURSO RETÓRICO}

En el primer párrafo del cuerpo de la noticia se desvela que el tamaño al que se refiere el titular y la entradilla no es el del pene, sino el de una hamburguesa:

La cosa es una hamburguesa gigante, una invasión de carne, queso, lechuga, cebolla y salsa que entra por los ojos directamente al corazón... del colesterol. Es la XXL, ración mayúscula, calorías en manifestación, una multiplicación por dos de las hamburguesas tradicionales.

El texto se inicia con el sustantivo cosa. Se trata de una palabra-baúl o pro-forma aplicable a todo objeto o acción, con una carga despectiva que intenta nuevamente rebajar la importancia del hecho relatado. Es un recurso atenuador de la gravedad del incumplimiento del acuerdo por parte de la cadena de restaurantes. El redactor introduce de nuevo la jocosidad para despertar la hilaridad del lector, que seguirá leyendo la noticia en clave de humor, intentando persuadirle de que la decisión de Burger King de promocionar la hamburguesa gigante carece de verdadera importancia, aunque el periodista reconozca que la empresa ha incumplido el acuerdo.

El texto describe la hamburguesa de forma hiperbólica: califica el producto mediante la metáfora bélica invasión [de varios ingredientes], la metáfora manifestación [de calorías], que destaca la aglomeración o multitud, y la aposición multiplicación por dos, que enfatiza que el tamaño es el doble del normal. La estrategia polifónica del periodista consiste en reproducir irónicamente el discurso del ministerio mediante la exageración de su argumento. Sanidad afirma que el tamaño de las hamburguesas excede el que las empresas se han comprometido a promocionar, y este discurso, mediante la hipérbole polifónica, se convierte, en el relato periodístico, en una "invasión de carne [...], calorías en manifestación, multiplicación por dos [...]”. El redactor finge asumir el discurso ajeno del ministerio, pero en el fondo lo rechaza mediante su ridiculización irónico-hiperbólica. Es una operación de manipulación discursiva de carácter desafiante, pues reconoce el gran tamaño y el exceso de calorías de la hamburguesa, pero al mismo tiempo se burla de ello, como si le divirtiera el hecho.

El redactor reconoce incluso que aumenta el colesterol de los consumidores -“ “...] entra por los ojos directamente al corazón... del colesterol [...]"-, aceptando, por tanto, que es perjudicial para la salud, pero la forma de enunciar este reconocimiento es también irónica, como si el periodista quisiera dar a entender que en este caso la salud es "cosa de risa". La modificación estructural de la unidad fraseológica entrar por los ojos mediante la adición del segmento "directamente al corazón... del colesterol" y el empleo de los puntos suspensivos son dos nuevos recursos lingüísticos que aportan el tono irónico a ese aparente y parcial reconocimiento de la influencia negativa de la hamburguesa sobre la salud humana. 
El autor de la noticia continúa con el uso de la estrategia polifónica en el siguiente fragmento. El periodista reproduce mediante una cita directa y textual el anuncio objeto de la polémica:

Cómete dos enormes y jugosas porciones de carne hechas a fuego, acompañadas por dos lonchas de queso, lechuga y cebolla naturales, pepinillos al eneldo y nuestra exclusiva salsa King, el secreto mejor guardado de Burger King. ¡Después no habrá nada que se te resista!

Así pues, en el artículo se hace mención y no uso del anuncio, pero su reproducción literal por parte del periódico supone una difusión indirecta y encubierta de la campaña publicitaria de Burger King.

A continuación el periodista vuelve a reconocer, pero minimizándolos mediante el uso de la ironía, los excesos de la hamburguesa, a la que describe como "cargamento de grasa sabrosa", repitiendo el empleo de metáfora bélica. Se trata de una nueva estrategia polifónica que pretende exagerar irónicamente el discurso médico y sanitario, que nos advierte de los peligros del abuso de las grasas (especialmente de las animales, uno de los componentes de las hamburguesas).

El autor invoca la "libertad individual" como argumento contra el intervencionismo estatal:

Promocionar ese cargamento de grasa sabrosa no pasaría de una apelación a la libertad individual de quien la quisiera engullir si no fuera porque hace casi dos años la propia empresa Burger King se comprometió a no dar publicidad a productos gigantes.

El periodista introduce una opinión de forma explícita: la licitud de la campaña publicitaria de la hamburguesa gigante en nombre de la libertad individual de los consumidores, independientemente del posible daño a la salud. Además, califica a la hamburguesa de sabrosa. De esta manera, el autor sitúa los términos del debate en una doble disyuntiva: libertad individual/salud y placer (sabor)/salud, y se inclina por el primer elemento de las dos bipolaridades.

Sin embargo, pone un límite a la legitimidad de la campaña: el hecho de que la empresa se comprometiera con el ministerio a no incentivar el consumo de raciones grandes. El incumplimiento del compromiso es un hecho irrebatible que el redactor se ve obligado a admitir, pero que tratará de minimizar mediante la ironía. Como estrategia retórica de mostrarse razonable asumiendo el argumento ministerial sobre el incumplimiento de un convenio, el redactor no tiene inconveniente en reproducir también literalmente el artículo del acuerdo firmado por la organización empresarial de las cadenas de restauración (FERHCAREM) y la Agencia Española de Seguridad Alimentaria (AESA):

$\mathrm{El}$ artículo $5^{\circ}$ de aquel convenio abre textualmente estas comillas:

"Raciones gigantes: las empresas Ferhcarem, con el objeto de no promover la ingesta excesiva de alimentos, se comprometen a no incentivar el consumo de raciones o porciones individuales gigantes".

El redactor aclara que es una cita textual, para que el lector no tenga dudas de que el texto reproducido es una mímesis total de un discurso ajeno. Con ello, el periodista 
enfatiza su intención de aceptar la inapelable acusación ministerial de incumplimiento de un acuerdo por parte de la cadena de alimentación. Una vez asumido este argumento del adversario gubernamental, el periódico informa de que este acuerdo fue ratificado dentro de la estrategia NAOS, un conjunto de medidas políticas para luchar contra la obesidad promovida por el Gobierno de España, incidiendo una vez más en la idea del acuerdo entre empresa y administración sanitaria. Sin embargo, nuevamente acompaña esta estratégica asunción del argumento contrario de una predicación irónica de la estrategia NAOS: la llama "la madre de todas las iniciativas políticas y empresariales para una alimentación equilibrada". El empleo hiperbólico del superlativo árabe es el mecanismo lingüístico de intención irónica con que el redactor trata de ridiculizar el plan gubernamental para combatir la obesidad.

Sigue el texto con otro reconocimiento irónico del gran tamaño de la hamburguesa: "raciones descomunales, hamburguesas a dos manos que alertaron a la AESA". Se exagera nuevamente el discurso ministerial -asumido por el sector empresarial de las cadenas de restauración moderna mediante, que puso su firma en el documento de compromiso-, al convertir burlonamente "ingesta masiva" o "porciones individuales gigantes" en "raciones descomunales, hamburguesas a dos manos", al igual que había hecho anteriormente el redactor, al convertir el discurso de Sanidad en ese discurso irónico formado por expresiones como "invasión", "manifestación", "ración mayúscula" y "multiplicación por dos".

El siguiente párrafo dice:

En Sanidad cuentan que la multinacional aclaró entonces que no había lanzado la campaña publicitaria a sabiendas de que incumplía la estrategia NAOS y que iba a estudiar el asunto.

Obsérvese el empleo distanciador del verbo de comunicación que introduce el discurso ministerial: cuentan, en tercera persona. El uso de la impersonalidad y el empleo del verbo contar -frente a otros más expositivos como afirmar, asegurar, señalar- pretende restar valor, credibilidad y autoridad al ministerio, ignorando deliberadamente la identidad de la fuente, en clara señal de menosprecio.

La noticia continúa con una nueva estrategia predicativa para describir a la hamburguesa: "la hamburguesa de Gargantúa y Pantagruel sigue rebosando calorías y grasas en las vallas [...]". La ironía se basa lingüísticamente en esta ocasión en la perífrasis humorística, al calificarla por medio de dos personajes literarios famosos por sus excesos gastronómicos. La visión jocosa de la hamburguesa tiene la función retórica de restar importancia al tamaño de la hamburguesa, atenuar su nocividad, rebajar la seriedad de la noticia y minimizar la gravedad del incumplimiento del convenio.

Ante la tentación gastronómica ofrecida por Burger King -hamburguesa de "carne, lechuga, cebolla y salsa que entra por los ojos", "sabrosa", "de Gargantúa y Pantagruel”-, afirma el periodista: “Terrible ser vegetariano, ¿verdad?”. Reproduce $\mathrm{y}$ asume el eslogan publicitario de Burger King, que pondera las bondades de su producto, haciendo un elogio de la hamburguesa al señalar la dura privación a la que se ven sometidos los vegetarianos, que tristemente deben renunciar al placer de comer un alimento rico como la hamburguesa gigante.

El redactor informa seguidamente del peso y las calorías de la hamburguesa, según los análisis realizados por la AESA: 328 gramos y 971 kilocalorías, en su intento de no 
ocultar datos que le son desfavorables, pero que asume irónicamente, lo que constituye una forma de aceptar los argumentos contrarios de manera desafiante. A continuación hay una exposición seria y explícita del argumento ministerial, según el cual

[existe una] relación directa e inequívoca del tamaño de la ración con la obesidad, sobre todo en niños y adolescentes. Todas las guías nacionales e internacionales de tratamiento de la obesidad recomiendan reducir y controlar el tamaño de la ración.

Sin embargo, a pesar de citar el argumento del adversario sin introducir la ironía en el discurso reproducido, como es una constante en la noticia, nombra a aquél mediante una perífrasis irónica con la que se ridiculiza a la Ministra de Sanidad, rebajando así su autoridad y restando seriedad al asunto: "Al Ministerio de la delgadísima Elena Salgado le preocupa la relación [...]", aludiendo a la delgadez de la titular del departamento, en un uso del argumento ad hominem.

A continuación, el periodista informa que "en los laboratorios de AESA se ha descubierto que el $20 \%$ de la hamburguesa XXL es grasa y que, de esa cantidad, un $38 \%$ es grasa saturada". El irónico redactor afirma seguidamente:

Es decir, en números absolutos, por cada ración XXL se ingieren 25 gramos de grasas saturadas, asegura el Ministerio de la moderación, el mismo que un día recomienda desayunar leche, cereales, frutas y fiambres y al siguiente ahuyenta al pueblo de las meriendas colosales.

A la predicación jocosa e irónica -califica al departamento encargado de la salud de Ministerio de la moderación, burlándose de su política de contención y prudencia alimentaria-, se une una falacia: se acusa al ministerio de incoherencia destacando el hecho de que recomienda, por una parte, desayunos copiosos y, por otra, meriendas moderadas. De forma simplista, el periodista pone al mismo nivel productos de diferente naturaleza nutricional, como son las hamburguesas con excesivas grasas saturadas para la merienda, y los alimentos vegetales sin grasas (frutas y cereales) y los productos con menos grasas (leche, que puede ser desnatada, y fiambres). Además, el redactor no indica las cantidades recomendadas por el ministerio en el desayuno, ni el hecho de que Sanidad incluye en sus consejos la leche, los cereales, las frutas y los fiambres como opciones diferentes, para que el consumidor elija algunos de estos productos, no necesariamente todos en cada ingesta.

Los dos últimos párrafos sirven de cierre al artículo. El articulista abandona, en parte, el tono irónico y jocoso y adopta una postura seria. En el penúltimo parágrafo introduce una cita directa y literal, entrecomillada, del director ejecutivo de la AESA, al que se refiere indicando su nombre propio y cargo. En el texto reproducido se afirma que la comercialización de las hamburguesas XXL no es ilegal, que no se cuestiona su calidad e inocuidad, y que tan sólo se pide a Burger King que no publicite las hamburguesas, en cumplimiento de su compromiso. Se enfatizan la legalidad y la calidad de la hamburguesa, puestas además en boca del adversario, lo que reduce la fuerza argumentativa y persuasiva del tamaño del producto y del incumplimiento de un pacto, que, mediante la ironía, no pasa de ser una decisión de la empresa presentada como jocosa, a través de una noticia llena de humor destinada a producir efectos cómicos en el lector, más que reflexivos y racionales. 
La inclusión de esta cita parcialmente favorable a Burger King, en que un responsable ministerial, adversario dialéctico de la empresa denunciada, reconoce abiertamente la legalidad de las hamburguesas, es una estrategia retórica que pretende minimizar la maldad de la hamburguesa y destacar el hecho de que la cadena de restaurantes no ha cometido una falta tan grave. El efecto persuasivo del argumento es mayor teniendo en cuenta que el reconocimiento procede de la misma instancia administrativa y sanitaria que denuncia a la empresa. Además, la cita parcialmente favorable a Burger King está estratégicamente situada casi al final de la noticia, en un lugar privilegiado, casi como cierre del texto, aprovechando el hecho de que los argumentos o ideas dispuestos al final se recuerdan por el lector con más facilidad y ejercen mayor impacto, pues se retienen como conclusión, síntesis final o idea más importante del discurso. El periodista no abandona totalmente la ironía, pues califica la campaña de Burger King de carnestoléndica, burlándose de la moderación ministerial.

Para terminar el texto, en el párrafo final, el redactor cede la palabra a la empresa denunciada, sobre la que han caído las críticas, sin introducir un atisbo de ironía, ya que la cita contiene el argumento asumido y defendido por el periodista:

La respuesta llegó a última hora. "Burger King siempre trabaja para reducir los riesgos de las enfermedades generadas por una dieta inadecuada y para promover una alimentación variada y equilibrada, sostuvo la empresa en un comunicado". Pero, unas líneas más allá, Burger King aclaró sus prioridades: "los gustos e intereses de nuestros clientes priman por encima de todo".

La cita entrecomillada encierra los argumentos de la empresa, asumidos implícitamente por el diario, que se sitúan en posición textual destacada, al final de la noticia, para que el lector conserve en la memoria el punto de vista del agente social apoyado por El Mundo. La cita reproduce las directrices comerciales que guían la política de Burger King: preocupación por una alimentación sana, pero obligación de atender los gustos e intereses de los clientes. El periódico, que ha tomado partido por la cadena de restaurantes, destaca como idea de cierre los argumentos con que la empresa se defiende, afirmando que se preocupa por la salud, si bien intenta que la administración y los ciudadanos entiendan que la empresa está obligada a atender los lícitos intereses de los clientes. Implícitamente, al recurrir al argumento de que los clientes son la prioridad, se está recordando la licitud de su decisión, ya que los clientes son soberanos en una economía de libre mercado. La empresa -y el periódico- está invitando al lector y al ciudadano a que se pongan en su papel de cliente, explotando el principio, tan de su gusto, de que "el cliente siempre tiene razón", de gran fuerza persuasiva en cualquier debate. El mensaje que pretende lanzar la cadena alimentaria, asumido por el periodista, es que la salud es un valor que la empresa no olvida, pero la libertad de mercado es el principio que rige principalmente su actividad económica, como está aceptado por la mentalidad hegemónica de nuestra sociedad.

El periodista ha empleado constantemente la ironía para burlarse del argumento irrebatible empleado por Sanidad de que Burger King ha incumplido su compromiso con la salud. Ante la imposibilidad de rebatirlo con argumentos sólidos, el periodista recurre a la ironía, aceptando el argumento del litigante, pero ridiculizándolo para rebajarlo a una idea sin importancia, a una idea hilarante y menospreciable. El redactor no niega que la empresa no haya respetado el convenio en defensa de la salud firmado con el Ministerio de Sanidad, sino que lo admite, pero mediante la burla y 
el menosprecio irónico, para reducirlo a un argumento poco pertinente en la controversia. El periódico adopta esta postura: acepto tu argumento, pero me río de él, lo menosprecio y lo considero irrelevante comparado con el argumento que yo defiendo, la libertad de mercado.

\section{SÍNTESIS: MECANISMOS LINGÜÍSTICO-RETÓRICOS DE LA IRONÍA}

A través de esta noticia, podemos ilustrar algunos de los mecanismos lingüísticoretóricos por medio de los cuales se materializa verbalmente la ironía:

- discurso repetido: en este caso, manipulado gramatical y semánticamente mediante la sustitución: El tamaño no importa se convierte en El tamaño sí importa.

- metáfora: precio cobrado en obesidades futuras, invasión de carne [...], calorías en manifestación, cargamento de grasa sabrosa.

- hipérbole: ración mayúscula, cargamento, madre de todas las iniciativas políticas, raciones descomunales, hamburguesas a dos manos, hamburguesa de Gargantúa y Pantagruel, merienda colosal.

- perífrasis: hamburguesa de Gargantúa y Pantagruel.

- palabras baúl: cosa [hamburguesa].

- construcciones enfático-ponderativas: todo un ministerio.

La noticia analizada es una muestra del empleo de la ironía como recurso retórico en una controversia periodística en el campo de la información sobre biopolítica y alimentación, cuyo fin es rechazar la postura del adversario aceptando parcialmente uno de sus argumentos irrebatibles, pero rebajando su importancia y su gravedad mediante la ridiculización. Si desde el punto de vista de la retórica elocutiva, ironía es una figura de ficción ligada a la sermocinatio, desde el punto de vista de la retórica argumentativa es una forma de concessio, es decir, una forma de aceptar un punto de vista del adversario, pero presentado como algo poco importante y escasamente relevante.

\section{OBRAS CITADAS}

Azaustre, Antonio y Juan Casas. 2006. Manual de retórica española. Barcelona: Ariel.

Berrendoner, Alain. 1982. Elementos de Pragmática Lingüística, Barcelona: Gedisa, 1987

Ducrot, Oswald. 1984. El decir y lo dicho. Polifonía de la enunciación. Barcelona: Paidós.

Gutiérrez Ordóñez, Salvador. 2003. Comentario pragmático de textos polifónicos. Madrid: Arco/Libros.

Haverkate, Henk. 1985. "La ironía verbal: un análisis pragmalingüístico". Revista española de lingüística 15.2: 343-392.

Leonetti, Manuel. 1999. El artículo. En: Bosque, Ignacio y Violeta Demonte. Gramática descriptiva de la lengua española, vol. I, pp. 787-890. Madrid: Espasa.

Lausberg, Heinrich. 1966-1969. Manual de retórica literaria. Fundamentos de una ciencia de la literatura. Madrid: Gredos.

Morata Garavelli, Bice. 1988. Manual de retórica. Madrid, Cátedra. 